\section{The effects of explicit pronunciation instruction on the comprehensibility and intelligibility of Tunisian EFL learners}

\author{
Bouchhioua, Nadia $\measuredangle$ \\ Faculty of Arts and Humanities, University of La Manouba, Tunisia (bouchhioua_nadu@yahoo.fr)
}

\begin{tabular}{lll}
$\begin{array}{l}\text { Received: } 1 \text { March } 2016 \\
\text { Available Online: } 11 \text { August 2016 }\end{array}$ & Revised: 17 May 2016 & Accepted: 10 July 2016 \\
\hline
\end{tabular}

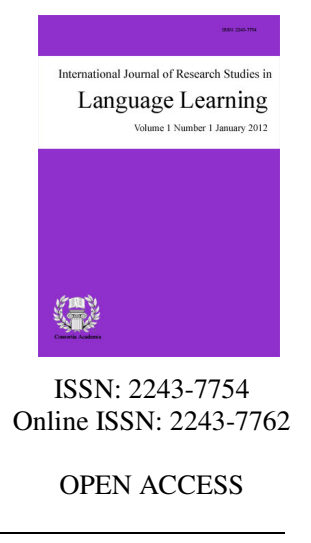

\title{
Abstract
}

Pronunciation instruction had often been neglected in English as a Foreign Language (EFL) classes because it was generally associated with the mechanical drills reminiscent of the Audiolingual method and because it was considered to be incompatible with Communicative Language Teaching (CLT). Recent research has, however, shown that explicit pronunciation instruction is quite compatible with CLT and that it results in improving the learner's comprehensibility and intelligibility. This study reports results of classroom-based experimental research on the effects of explicit pronunciation instruction on the learning of the segments and suprasegmental features of English by Tunisian EFL learners. It followed a pretest /posttest design. Two experimental groups (Groups $1 \& 2$ ) received a special treatment in pronunciation using an eclectic approach. Group 1 was taught pronunciation with a focus on English segments, while with Group 2 the focus was rather on suprasegmental features. The performance of the two groups was compared to a control group (Group 3) that was taught the same content but following the traditional Audiolingual method. Native speakers of American English rated the comprehensibility of the participants and transcribed some of their utterances before and after the treatment. Results show that both the comprehensibility and the intelligibility of Tunisian EFL learners' speech improved significantly. Group 2 which had more practice in suprasegmentals obtained, however, better results than Group 1 which had more practice on segments. Implications for pronunciation teaching and syllabus design are hence put forward.

Keywords: prosodic; prosody; suprasegmental features; segments; Arabic learners 


\section{The effects of explicit pronunciation instruction on the comprehensibility and intelligibility of Tunisian EFL learners}

\section{Introduction}

The effectiveness of second language (L2) pronunciation instruction has been disregarded in the last decades and has not been granted as much importance as other subjects. This may be due to the results of many studies (Larsen-Freeman \& Long, 1991; Oyama, 1976; Asher \& Garcia, 1969; Major, 1987) that suggest that native-like pronunciation in a second language is impossible to acquire unless exposure to the second language is started at a very early age. The traditional approach in pronunciation teaching placed focus on the acquisition of native like pronunciation through the teaching of separate segments (consonants and vowels) no-communicatively and through drills of isolated words, which was frustrating for many learners. However, in the research-based approach the goal is to acquire a pronunciation that does not inhibit communication by giving priority to the teaching of suprasegmental features (also called prosody or prosodic features, such as word and sentence stress, rhythm and intonation) in a communicative way that would enable learners to speak intelligibly and in a comprehensible way. Researchers such as Scarcella and Oxford (1994) think that although most adult learners are incapable of acquiring a native-like pronunciation skill in a second language, they "can improve their pronunciation themselves when teachers provide them with many types of assistance" (p. 225). Learners of L2 pronunciation can certainly develop an intelligible speech in the second language when they participate in their own learning, form new concepts of the target language sound system (Couper, 2009; Fraser, 2009), and when the teacher backs them up through a variety of techniques that foster the efforts they make to produce a comprehensible and an intelligible speech.

Intelligibility is, in fact, defined by Derwing and Munro (2005, p. 385) as "the extent to which a listener actually understands an utterance", while comprehensibility is defined as "a listener's perception of how difficult it is to understand an utterance"(ibid). Though the two terms are closely connected and are difficult to dissociate since the ability of understanding an utterance depends on ease of its perception, they do present reasonable goals in the quest of teaching pronunciation to second language learners. They avoid the frustration that many learners may experience in their journey of trying to acquire a native-like accent, especially, if pronunciation instruction is carried out in a communicative way. The general practice in Communicative Language Teaching (CLT) classes is that either pronunciation is not taught at all or it is taught implicitly without raising the learners' awareness to the importance of accurate pronunciation to communication. This practice is usually justified by the belief that fluency development is much more important than accuracy as it helps the learner to gain self-confidence and reduce his/her frustration by focusing on meaning rather than form. Accuracy is considered a key factor in communicative competence as successful communication cannot take place without correct pronunciation and poorly pronounced segments and supra-segmental features may have the result of disorienting the listener and inhibiting comprehension. In fact, the Communicative Approach with its heavy emphasis on input was thought to indirectly improve pronunciation through exposure to target language and without any explicit instruction. Terrel (1989) states that "the ability to produce L2 sounds and use them according to their correct patterning in the TL [target language] would automatically develop by listening to and understanding input" (p. 207).

Elliott (1995), however, found that pronunciation when not formally taught remained relatively constant and did not improve in spite of the high degree of input the learners processed. Hence, derives the importance of explicit pronunciation teaching even within a communicative approach. Various pronunciation studies have, actually, shown the positive effects of explicit pronunciation instruction (Lord, 2005; Saito \& Lyster, 2012; Elliot, 1997) as adult learners in those studies were found to improve in accuracy of pronunciation after explicit trainings. Couper (2003) surveyed learners' attitudes towards explicit pronunciation instruction. His results 
showed that the majority of the participants preferred the systematic explicit instruction carried out in the study and considered it as important. Derwing and Munro (2005) also asserted that phonological forms should be explicitly taught to students, which helps them to perceive the differences between native speakers' pronunciation and their own pronunciation.

Advocates of the cognitive framework in language teaching [that is, Cognitive Phonology, in Langacker (1987) and Taylor ( 2002)] also stressed the importance of pronunciation instruction, with the goal of reaching an intelligible rather than native like accent, since it can lead to positive results. Pennington (1998) argued that explicit instruction can raise learners' degree of awareness of their own phonological acquisition process and their own pronunciation patterns and problems. Fraser (2006) advocated that there is a major cognitive component in pronunciation learning, which is much less often admitted and believes that it is useful to think of learning to pronounce a new language as involving a kind of "concept formation" rather than as a purely physical skill. The author argues that learners of English, for example, have the (physical) ability to produce stressed syllables, but what they generally have difficulty with is the concept of stress itself which is language specific and how to use it in the new language. A better understanding of the conceptual aspects of pronouncing a new language such as word stress patterns would therefore help both teachers and learners. Implementation of tasks and activities that would assist learners in developing new concepts of the sounds and the prosody of the target language should, however, take place in communicative contexts. Learners would profit greatly if explicit explanation of how pronunciation suits the general process of communication is presented to them through authentic situations meant for practice together with critical listening activities that assist learners in comparing and contrasting the differences between their perceptions of the target language phonology and the native speaker's perception (Couper, 2009, 2011; Fraser, 2009).

Comparing the role of segments to suprasegmental features in the improvement of learner's pronunciation of the target language, research evidence shows that suprasegmentals play a more important role than segmentals. Anderson-Hsieh, Johnson, and Koehler (1992) compared the relative contributions made to intelligibility by prosodic features, segments, and syllable structure and found that the score for suprasegmentals was significantly associated with the overall score for pronunciation. Earlier, Anderson-Hsieh and Koehler (1988) also found that "prosodic deviance may affect comprehension more adversely than does segmental deviance" (p. 562). Derwing, Munro, and Wiebe (1998) investigated the effects of both segmental and suprasegmental instruction on learners' comprehensibility ratings through a study that compared three ESL (English as a Second Language) classes receiving different treatments (segmental focus, global speaking habits and prosody, and no specific pronunciation instruction). Their results also revealed that prosody had a much more important effect on performance in communicative contexts as the group which had an instruction focusing on suprasegmentals improved better in fluency than the two other groups.

In a related recent study, Gordon, Darcy, and Ewert, (2012) as well found that the teaching of suprasegmental features of the L2 improves comprehensibility more than the teaching of separate sounds does. Similar results of the importance of the role of suprasegmentals in perceived comprehensibility are also reported by Phan and Vo (2012). Developing a respectable, comprehensible and intelligible pronunciation seems therefore possible to reach especially if focus is placed on the teaching of prosody and if the research-based rather than the traditional approach is adopted in instruction. Most of these studies are, however, carried out in ESL contexts where learners from different first language (L1) backgrounds live in an English speaking country and learn pronunciation together in ESL classes. Further research is, nevertheless, needed to verify how learners from a common first language (L1) background, with specific pronunciation difficulties, and who are learning their target language in an EFL (English as a Foreign Language) context respond to explicit pronunciation instruction.

The present study abides by Derwing et al. (1998) and Gordon et al. (2012) in its experimental design which consists in comparing the performance of three groups after a treatment in pronunciation instruction with special focus for each group. However, it differs from both studies in that it is carried out in an EFL rather than an ESL context and that it addresses a group of learners from the same first language background. More 
importantly, the present study differs in the teaching approach its adopts which is based on Fraser's (2009) suggested focus on the cognitive aspects of pronunciation in forming phonological concepts. This approach is implemented eclectically by combining CLT and the cognitive frame work principles and techniques in the lessons. The other difference is that the present study uses as a control a group of learners who receive pronunciation instruction in the traditional Audio-lingual way with no specific focus on either segments or prosody of the target language, and hence it tries to assess the impact of the teaching method as well.

\subsection{Motivation and context of the study}

The Tunisian EFL context suffers from a great lack of research in pronunciation instruction, mainly explicit pronunciation teaching in EFL contexts in comparison to other areas such as morpho-syntax, reading and writing skills, and vocabulary learning. In addition, a few teachers receive adequate training in how to teach pronunciation to EFL learners. This is aggravated by the lack of research-based text books and materials for pronunciation teaching that can be adapted by teachers. At the secondary school level, students have three hours of English a week on average. A standard official book designed by the ministry of education is used. Pronunciation teaching is almost absent. At the end of each unit of the text book, you find tasks such as Put $S$ (similar) or D (different) for the underlined sounds: Father --- Mother ( ) Son --- Sun ( ) ' or ' circle the stressed syllable: Economy - Economic-Economical with no audio files, just from orthography or according to the teacher's pronunciation.

Elkassami (2014) surveyed secondary school teachers' perceptions of pronunciation teaching and found that those EFL teachers who are 100\% non-native speakers of English generally neglect pronunciation teaching. Some of them see it is not important to teach pronunciation and students will manage by themselves to learn it. Others see it is important, but they always have no time for it and think they have to cover "much more important" skills in the syllabus such as grammar, vocabulary, reading, and writing. These views are reinforced by the testing system adopted and the distribution of marks in the English test as most marks are allocated to the skills above and only few marks go to pronunciation, if it is tested at all. This disregard of pronunciation teaching and the underestimation of its importance for communication resulted in the failure of a large number of learners to develop an intelligible pronunciation. In fact, even students who choose to major in English report to be too shy to speak in public, and generally feel embarrassed to present any assignments orally because they think their pronunciation is not" good enough" (Elkassmi, 2014).

As far as university teachers are concerned, according to Elkassami's (2014) survey those teachers acknowledge the importance of pronunciation teaching, especially connected speech and its characteristics. However, they report being faced by two main challenges when teaching pronunciation. The first challenge is the lack of appropriate materials that meet the needs of the students, and second is the lack of specific training on how to teach pronunciation. Elkassmi's (2014) findings about teachers' perceptions and cognitions of the importance pronunciation teaching are quite similar to the findings of other studies carried out in different contexts such as Backer (2014). The common practice for teaching English pronunciation in Tunisian universities, specifically for English major students, is that a pronunciation book is adapted and some production and/or perception activities are chosen randomly and practiced in the audio-lingual way. The problem is that almost all English pronunciation courses are standard and are considered suitable for any foreign learners whatever their first language background is. This is because the focal point of these books is the target language pronunciation and its different aspects, regardless of the learners L1 features that may interfere in the process. Tunisian EFL learners, as a result of this practice, failed to develop accuracy in pronunciation, especially if the accent taught is Received Pronunciation (RP) that most students according to Selmi (2012) report as hard to acquire and prefer American English to it.

The general conclusion, here, is that pronunciation teaching in the Tunisian EFL context has been carried out haphazardly. No identification of the weaknesses or special difficulties of these learners is performed. No training in pronunciation teaching is at all provided for teachers. In addition, these learners have not been 
reassured that their pronunciation can be improved, that it does not matter if they have a foreign accent, and that the most important thing is to be intelligible and comprehensible when speaking English to both native and non-native speakers. A much more successful pronunciation instruction practice would be based on a deep knowledge of the learners' native language sound system and its prosodic characteristics. Such knowledge would enable the teacher to know exactly what to focus on, what the weaknesses of learners are, and what aspects of the first language sound system (Tunisian Arabic in this case) interfere with the learning of the English sounds and prosodic features and negatively affect the comprehensibility and/or the intelligibility of the learner's speech. In addition, if instruction is carried out following an eclectic approach that explicitly instructs learners and raises their awareness to the importance of accurate pronunciation abiding by the principles of Cognitive Phonology in considering that L2 pronunciation difficulties are more related to cognitive factors than to physical ones (Fraser, 2000; Pennington, 1998) and if this is combined with teaching pronunciation in the context of meaningful interaction rather than as an isolated skill that is to say following the principles of the Communicative Approach, then better results could be achieved as more opportunities for interaction and practice would be provided for the learner.

To verify this hypothesis, the following research questions are hence asked:

$>$ Does explicit pronunciation teaching (through focusing on the particular difficulties of a group of learners and adopting the principles of Cognitive Phonology) result in more intelligibility and higher comprehensibility?

$>\quad$ Where can we see better results of pronunciation instruction, at the segmental or the suprasegmental level?

Before presenting the methodology that has been followed in order to answer the research questions, a brief survey of the problematic pronunciation areas for Tunisian EFL learners is provided.

\section{A review of the literature on the pronunciation difficulties of Tunisian EFL learners}

\subsection{Segmental duration}

Producing longer vowels and syllables than native speakers of English do is a tendency often noticed among EFL learners from different L1 backgrounds, including Tunisian EFL learners. Bouchhioua (2008) found that the production of English stressed and unstressed vowels, as well as whole words, in focused and non-focused conditions by Tunisian EFL learners was constantly longer than those of native English speakers. Similar finding concerning length are reported by Cheikrouhou-Smaoui (2003) who found that Tunisian EFL learners produced longer English vowels and syllables than native speakers do. Actually, we often hear Tunisian EFL learners substituting the short lax vowel /I/ by its tense counterpart/i:/ through producing a longer vowel in words like ' big, give, kill, did, live, ship', which would not only reveal their non-native status, but can also affect their

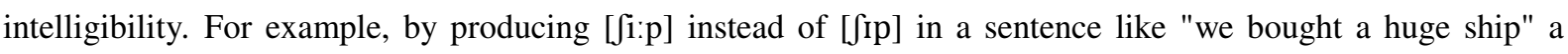
completely different meaning can be conveyed if the vowel in "ship" is lengthened (giving "sheep" instead) and consequently intelligibility can be affected. The difference between /i:/ and /I/ in English is, however, not simply a matter of length, but also of vowel quality since these two vowels differ in terms of tenseness as well. The same confusion happens between the vowels $/ \varepsilon /$ and $/ \mathfrak{æ} /$ and the vowels $/ \mho /$ and $/ \mathrm{u} /$. Therefore, focusing on teaching vowel quality and explicitly explaining segmental differences and their importance for conveying the appropriate message (through an English pronunciation course that is designed to specifically address these features) would help Tunisian EFL learners overcome such difficulties and avoid intelligibility problems.

\subsection{Suprasegmental features: lexical and phrasal stress, weak forms, rhythm, and intonation}

Ghazali and Bouchhioua (2003) investigated the production of English word stress and weak forms by 
Tunisian EFL learners and found that the stress rules of Tunisian Arabic (TA) seem to affect the way Tunisian EFL learners acquire the phonology of English lexical stress. In TA, final syllables are stressed if their rhymes are one of the following two types: VVC or VCC; otherwise, it is the penultimate that is stressed instead. Thus, most Tunisian students incorrectly put initial stress on until or upset, but final stress on backward. The rule that students were using, however, is precisely that which assigns stress to TA words. The authors also showed that students stressed function words in English sentences where they should be unstressed (weak forms) in more than $90 \%$ of the cases leading, thus, to intelligibility problems. The tendency of not making vowel reduction in function words is also noticed in the L2 English of learners whose first language is Ammani Arabic and Egyptian Arabic (Almbarik, Bouchhioua \& Hellmuth, 2014). At the phonetic level, Bouchhioua (2008) compared the acoustic correlates of word-level stress and phrase-level stress (accent/ focus) in TA and English and tried to determine whether L2 learners of English use the L1 or the L2 phonetic correlates of stress and accent in their productions. Results showed that much interference is caused by the use of the L1 stress correlates, mainly the use of the F0 (Fundamental Frequency) and the vowel quality correlates. EFL learners in the study produced English stressed vowels and syllables with a higher pitch, a greater intensity and much less vowel reduction than native speakers do. These findings about the acquisition of the phonology and phonetics of the feature stress by Tunisian EFL learners provide a useful background to the design of pronunciation activities that address these features openly and try to provide the right remedy.

Regarding the rhythm characteristics of L2 English as produced by Tunisian learners, Cheikrouhou-Smaoui (2003) compared speech rhythm in TA to rhythm in English when this latter is produced by both speakers of TA and native speakers of English. This study, based on the traditional method of measuring inter-stress intervals and syllable and foot durations, suggests that native English rhythm is stress-timed while TA rhythm is rather syllable-timed. Tunisian EFL learners in this study were close in their rhythm production of English to syllable timing, which means that they show a tendency for syllables to recur at regular intervals because the author found very little evidence for compression tendencies as a function of interval length. These findings reinforce the need to impart the characteristics of English rhythm to learners while teaching English pronunciation and to focus on reducing the tendency of those learners to produce a syllable-timed production rather than the required stress-timed rhythm by careful explanation of how the two types of rhythm are conceptualized by native speakers.

As far as intonation is concerned, Aloulou (2003) studied some of the basic TA intonation patterns and found that the falling tone is used in declaratives while a rising tone is used in non-final declarative sentences. She also found that the rising tone is typical of yes /no questions in TA. For wh-questions, the majority of the tones used by native speakers of TA were falling tones, $80 \%$ approximately. Exclamations and imperatives were produced with a prevailing falling tone, too, although both, fall-rise and rise-fall tones existed for imperatives. Comparing the five sentence types used in the TA sample to their English counterparts, the author found significant differences in the association of tones with each type of sentence in the two languages. The English and Tunisian subjects in this study used intonation patterns that were language specific; the author concludes (p. 118). More interestingly, intermediate EFL learners in this study used different intonation patterns (from those used by native English speakers) on almost all the sentence types, except in yes/ no questions and exclamations (p. 115). The author attributed this behavior to various factors, including interference from the native language's intonation patterns or the lack of exposure to native English speech by this group of subjects. Although the L1 impact was the major source of difficulty to which the pronunciation errors in these studies were attributed, other factors such as individual differences, motivation, as well as the degree of exposure to the target language are also believed to affect L2 phonological acquisition.

The conclusion drawn from the studies reviewed is that Tunisian EFL learners exhibit some transfer problems in the acquisition of English segments and suprasegmental features. They tend to unconsciously apply the rules of their native language sound system and prosodic features such as segmental duration, word stress, rhythm, or intonation in their pronunciation of English. Actually, the transfer theory has been criticized and rejected in many fields of second language learning, yet at the level of pronunciation its role has always been 
recognized especially in accounting for foreign accents and in relation to the acquisition of some segments and suprasegmental features of the target language (Celce-Murcia, Brinston, \& Goodwin, 2010). Explaining the difficulties of this group of learners in relation to the Cognitive Approach, it can be said that these learners have not been aided to form "new concepts" of this typologically distant language to theirs and did not understand the importance of producing the right segments and suprasegmental features to successful communication. Any general pronunciation course of English as a second language would fail to address these problems as it is not specifically designed to do so. Research in applied linguistics has as a main goal addressing the learners' specific needs and developing appropriate materials in order to improve the learning and teaching of the target language. It would, consequently, be efficient to design a research-based pronunciation course for Tunisian EFL learners focusing on the specific needs of this group of learners.

The current class-room based study, therefore, investigates the way explicit pronunciation instruction (through a syllabus that focuses on the special potential problems of Tunisian learners as spotted from the literature review + an eclectic teaching that provides explicit phonetic explanation and communicative tasks for practice) can contribute to a more comprehensible and intelligible speech. At the same time, the present study tries to test whether segments or suprasegmentals improve comprehensibility and intelligibility more.

\section{Methodology}

\subsection{Participants}

Initially, thirty six English major Tunisian students at a large Tunisian university and with same level of English proficiency (pre-intermediate as determined by a placement test), voluntarily participated in the study. They were equally and randomly distributed among three groups; groups 1 and 2 as experimental groups and group 3 as a control group. They were aged between 20 and 22 and were all native speakers of Tunisian Arabic. All of the participants started learning English at the age of 13 and none of them has lived in an English speaking country. However, because of absenteeism the final analysis included only 24 participants who attended all the lessons and took the pre and posttests. Three teachers taught the courses, one teacher for each group. The three teachers had Tunisian Arabic as their mother tongue and had equal university degrees. They also had about the same teaching experience (from 7 to 8 years). However, none of them had received any training in pronunciation teaching. Five Native American English speakers also participated in the study as raters of the learners' comprehensibility. They were students of Arabic in Tunisia and have been in the country for three months at the time of the experiment. They were between the age of 22 and 26, had normal hearing and no teaching experience in any field.

\subsection{Instruction}

The study followed the experimental design of pretest-posttest. The two experimental groups (Group1 and 2) received a treatment of one hour pronunciation instruction over eight consecutive weeks. The course adopted an eclectic approach, where a combination of methods is used in each lesson. For both experimental groups, each lesson starts by awareness raising towards the teaching point, explicit simplified phonetic content is then introduced (for example, the importance of producing the right vowel, stress pattern, or weak form of a function word for meaning in the target language, following the Cognitive Approach).Visual aids and phonetic charts are used. The content is then practiced through bottom-up skills such as minimal pair discrimination and recognition exercises. Short passages, short dialogues and conversations are listened to, and then read. At the production stage, top-down skills for the development of fluency are taught. These activities include communicative tasks such as pair and group discussions, role plays, information gap activities, etc... (following the Communicative Approach) and are followed by feedback from the teacher. Critical listening activities where learners record themselves, listen to their own productions or those of their peers and judge how different or similar they are from a native speaker model were also used. The two experimental groups differ by the amount of focus given to 
either the segmental or the suprasegmental level. The course with focus on the segmental level (Group 1) emphasized segmental contrast of for example the vowels /i:/ vs. /I/, /æ/ vs. / $/ \varepsilon /$ or consonants / $/ \mathrm{vs}$. /t $\mathrm{j} /$. Whereas, the course with a special focus on the suprasegmental level (Group2) focused on explicit phonetic instruction of suprasegmental features such as word stress, weak forms in function words, intonation and rhythm because of their importance for communication.

The control group (Group 3) was taught the same content but following a traditional approach where each lesson starts with a detailed theoretical phonetic description of the feature to be taught (for example technical description of the place and manner of articulation and state of the glottis for each English consonant, or a full phonetic description of English vowels in terms of tongue height and advancement, lip rounding and tenseness). For word stress, weak forms, and intonation, rules were given to students regarding these features in handouts. Lab drills are then practiced where students have to listen and repeat after a tape in an Audiolingual way. No particular focus was placed on either the segmental or the suprasegmental level during instruction.

The accent that the learners in the three groups listened to through audio-tapes and computers was North American English. All the treatment sessions were audio-taped and transcribed to check the implementation of the experimental design. Table 1 provides an overview of the three courses.

\section{Table 1}

A description of the course content for each group

\begin{tabular}{|c|c|c|}
\hline $\begin{array}{c}\text { Group 1 } \\
\text { Research-based instruction with } \\
\text { focus on the segmental level }\end{array}$ & $\begin{array}{l}\text { Group } 2 \\
\text { Research-based instruction with } \\
\text { focus on the suprasegmental level }\end{array}$ & $\begin{array}{c}\text { Group } 3 \\
\text { Traditional pronunciation } \\
\text { instruction ( control group ) }\end{array}$ \\
\hline $\begin{array}{l}\text {-Explicit instruction \& simplified } \\
\text { analysis of segmental features } \\
\text { (vowels+ consonants). }\end{array}$ & $\begin{array}{l}\text {-Explicit instruction \& analysis of } \\
\text { suprasegmental features (word } \\
\text { stress, weak forms, sentence stress, } \\
\text { intonation, and rhythm). }\end{array}$ & $\begin{array}{l}\text {-Technical phonetic description of } \\
\text { English vowels and consonants. }\end{array}$ \\
\hline $\begin{array}{l}\text {-A particular focus on the vowels } \\
\text { that are most challenging for } \\
\text { learners /(/i:/ vs./ I/, /æ/ vs./ } \varepsilon /, \text { ). }\end{array}$ & $\begin{array}{l}\text {-A particular focus on the most } \\
\text { problematic areas to Tunisian EFL } \\
\text { ( some specific word stress } \\
\text { patterns+ reduced \&weak forms, } \\
\text { intonation, rhythm). }\end{array}$ & $\begin{array}{l}\text {-Same content presented but with } \\
\text { no particular focus on the specific } \\
\text { difficulties for Tunisian EFL } \\
\text { learners. }\end{array}$ \\
\hline $\begin{array}{l}\text { - Awareness raising towards the } \\
\text { importance of producing the correct } \\
\text { segment to communication. }\end{array}$ & $\begin{array}{l}\text {-Awareness raising towards the } \\
\text { importance of the correct feature } \\
\text { use to communication. }\end{array}$ & $\begin{array}{l}\text {-No awareness raising of the link } \\
\text { between correct pronunciation and } \\
\text { successful communication. }\end{array}$ \\
\hline $\begin{array}{l}\text {-Guided practice on segment } \\
\text { articulation through minimal pairs } \\
\text { and sentences+ communicative } \\
\text { production tasks (story retelling } \\
\text { and summarizing, information gap } \\
\text { activities, role plays, etc). }\end{array}$ & $\begin{array}{l}\text {-Guided practice on word stress } \\
\text { patterns+ unstressed function } \\
\text { words, focus, contrast, etc... } \\
\text { +communicative production tasks } \\
\text { (story retelling and summarizing, } \\
\text { information gap activities, role } \\
\text { plays, etc, intonation in discourse } \\
\text { and for meaning). }\end{array}$ & $\begin{array}{l}\text {-Audio-lingual drills on separate } \\
\text { segments, words, phrases \& } \\
\text { sentences. }\end{array}$ \\
\hline -Critical listening activities & -Critical listening activities & \\
\hline
\end{tabular}

\subsection{Pretest and posttest}

Participants from the three experimental groups were audio-recorded individually before the treatment through a pretest, and after the treatment though a posttest. Recordings took place in sound-isolating room. The pretest included 15 sentences (Appendix A), while the posttest comprised the 15 sentences of the pretest plus 5 new sentences (Appendix B). All the sentences were carefully designed so that each contains at least one word 
with a target sound (a vowel or a consonant) studied by group 1" with focus on segments" or a weak form of a certain function word (preposition, article, etc...) studied by group 2 "with focus on suprasegmentals". In six of the sentences chosen, the weak form use is essential otherwise the meaning of the sentence changes completely. These six sentences were later used to test intelligibility. It is worth mentioning that none of the sentences used in the tests was taught during the course. The sound files for each sentence produced by each speaker in each group in the pre and posttests were given specific codes and labels. The sentences were then randomized and presented to the American listeners after the treatment. The listeners, thus, had to listen and rate sound files in a random order. The same procedure was followed for the transcription task.

\subsection{Data analysis}

Because some of the students from the three groups were not able to attend all the lessons, or withdrew for personal reasons, only the data from the students who took the pretest, attended all the lessons and completed the treatment and took the posttest was analyzed. The final analysis comprised 3 groups $\times 8$ participants $=24$ participants. Some participants did not accurately produce some of the sentences, or were hesitant and unclear. Therefore these sentences were discarded from the analysis, giving thus 10 sentences from the pretest and 14 sentences from the posttest. A total of 24 sentences $\times 8$ participants $\times 3$ groups $=576$ sentences was accordingly used in the comprehensibility rating task. For intelligibility measurements the data comprised 6 sentences $\times 3$ groups $\times 8$ participants, giving thus, a total of 144 sentences in the pretest and the same number in the posttest. The sentences were presented to 5 native speakers of American English. The raters listened to all the sentences (from pre and posttests) in a quiet room through good quality headphones attached to the computer. Each sentence was rated using a 9-point Likert scale ( $1=$ extremely easy to understand, $9=$ impossible to understand). This scale is common in comprehensibility measurements and was reported to provide reliable ratings (Derwing \& Munro, 1997; Gordon et al., 2012). The Native American English speakers were then asked to transcribe (write in orthography) what they hear in six of the sentences from 8 participants in each of the three groups to assess intelligibility. Measures of intelligibility vary from one study another, but the most common measure is making native speakers transcribe the utterances they hear. To avoid fatigue and the risk of boring the raters, the listening and the transcription tasks were carried out over several days and different times according to their availability and willingness.

\section{Results}

\subsection{Comprehensibility results}

The analysis started by checking the inter-rater reliability among the 5 American raters. The inter-rater reliability coefficients (Cronbach's alpha) were computed across the ratings given for each list of items presented to raters and were found to be high (.89 and .90), indicating therefore a strong agreements between the five raters. Then, abiding by the statistical design used in Gordon et al. (2012), the effect of sentence type (new vs. repeated) in the posttest and its interaction with group was the first factor to check statistically. It was found to be non-significant as the participants in this study received equal ratings for repeated and new sentences used in the posttest. This finding allowed dropping the factor new vs. repeated sentences from the statistical analysis. A general mixed effects model was adopted in the analysis. The factors test (pretest and posttest), and group (Group 1 "with focus on segments", Group 2 "with focus on suprasegmentals" and Group 3 "control group") were used as fixed effects while participants, items, and raters were used as random factors. The results revealed that there was a significant effect of the factor test $(F 1,1466=23.3, p<.001)$, showing thus an improvement from pre to posttest. There was also a significant effect of $\operatorname{group}(F 2,24=52.9, p<.001)$ and more interestingly a significant interaction between group and test was found $(F 2,1842=21.9, p<.001)$. This interaction shows that the groups obtained different ratings each time (that is to say in the pretest and in the posttest) and that this difference was the result of the kind of treatment they received. The mean ratings of comprehensibility for each group by the five American English speakers were computed to compare the performance of the three groups 
Bouchhioua, N.

before and after the treatment. Table 2 provides these means.

Table 2

Mean ratings of comprehensibility for the three groups in the two tests

\begin{tabular}{lccccc}
\hline \multicolumn{1}{c}{ Groups } & Pretest & $\begin{array}{c}\text { ( SE) } \\
\text { Standard error } \\
\text { of mean }\end{array}$ & Posttest & $\begin{array}{c}\text { SE) } \\
\text { Standard error } \\
\text { of mean }\end{array}$ & $\begin{array}{c}\text { Significance } \\
\text { level }\end{array}$ \\
\hline Group 1: segmental & 5.2 & .41 & 3.4 & .41 & $p<.05$ \\
Group 2: supra-seg & 5.4 & .41 & 2.99 & .41 & $p<.05$ \\
Group 3: control & 5.3 & .39 & 4.8 & .39 & $p>.05$ \\
\hline
\end{tabular}

Comparing the average ratings assigned for each group in the pretest to that of the posttest showed that while the performance of the control group improved only slightly, the performance of both experimental groups improved considerably. Group 2 "with focus on suprasegmentals", nevertheless, improved more importantly than group1" with focus on segments" showing thus the effectiveness of teaching suprasegmental in enhancing comprehensibility in L2 speech. Figure 1 provides a clearer visual display of the difference in performance between the three groups.

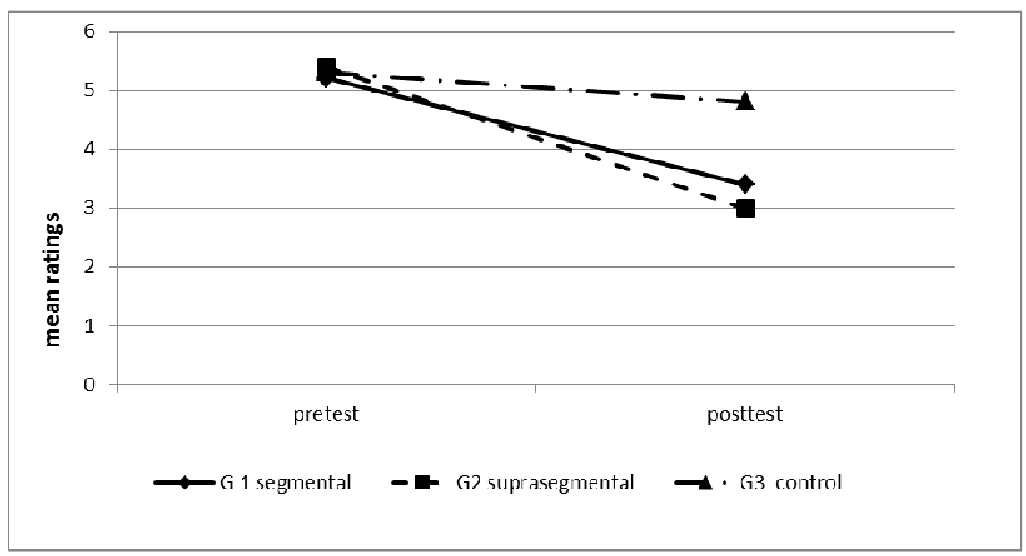

Figure 1. Comprehensibility mean ratings of the three groups before and after the treatment

\subsection{Intelligibility}

For the intelligibility analysis, the five raters were asked to transcribe (write in orthography) sentences they hear from 8 speakers in each of the three groups form the pretest and posttest. This listening and transcription task took place after the treatment had finished. The sentences from the two tests were codified and randomized before they were presented to listeners. Filler sentences were inserted to reduce the risk of familiarity with the target sentences. The inter-transcriber reliability coefficient was calculated across the transcriptions of the six sentences as they were produced by all the participants in the three groups. It was found to be high (Cronbach's alpha=.92), which shows that there is a strong "agreement" among the 5 American transcribers. The results obtained were analyzed using descriptive statistics because of the small number of sentences. Among the 48 sentences from the pretest that the five American speakers had to transcribe for Group 1"with focus on segments" ( $48 \times 5=240)$, only 23 sentences were correctly transcribed, that is, about $10 \%$. For Group 2" with focus on suprasegmentals", almost the same percentage was obtained (11.4\%), and a quite similar percentage for the control group (Group 3) as well, 11.1\%. Intelligibility in the pretest was severely affected as most of the raters provided wrong transcriptions of the target words they heard from participants in the three groups before the treatment. For example, the sentence "use the numbers one to four" was transcribed as "use the numbers one two four " in $85 \%$ of the times in the pretest items among the three groups simply because the speakers did not make the necessary vowel reduction in the function word to. The percentages of wrong transcriptions decreased significantly in the posttest items where the percentage for this sentence, for instance, dropped to $36 \%$ (about 86 correct transcriptions) for Group 1 and to about $40 \%$ (about 96 correct transcriptions) for Group 2. The total 
percentage of correct transcriptions in the posttest items thus augmented to $46 \%$ for Group 1 "with focus on segments", to $61 \%$ for Group 2 "with focus on suprasegmentals", and to only $14 \%$ for the control group. Table 3 provides an overview of how the mean of correct transcriptions has increased after the treatment for the two experimental groups but more importantly for Group 2, where much focus was assigned to the teaching of the suprasegmental features.

Table 3

Means of correct transcriptions of six sentences by the five American English speakers

\begin{tabular}{lccc}
\hline & $\begin{array}{c}\text { Mean of correct } \\
\text { transcriptions of pretest } \\
\text { sentences }\end{array}$ & $\begin{array}{c}\text { Mean of correct } \\
\text { transcriptions of posttest } \\
\text { sentences }\end{array}$ & SD \\
\hline Group 1: segmental & .60 & 2.41 & 1.280 \\
Group 2: supra-seg & .62 & 4.20 & 2.531 \\
Group 3: control & .61 & .98 & .262 \\
\hline
\end{tabular}

Just like for comprehensibility, the results for intelligibility show that the group that performed best in the posttest and seemed to benefit more from the treatment is the group which had more training on the prosodic aspects of English in communicative tasks and understood how important these features are for successful communication. The following section presents a discussion of the results.

\section{Discussion}

The results of this study are discussed from four complementary angles. First, the results show that implementation of the principles of the Cognitive Approach such awareness raising, explicit explanation, and developing new concepts about the sound system of the target language seem to lead to positive results in pronunciation instruction. Drawing learners attention to the importance of producing the right vowel or consonant, the right stress pattern or the right intonation to convey the right message is beneficial, especially when it is combined with critical listening activities where learners record themselves, listen to their own recordings, map or compare that to a native speaker model and see if the right message was communicated through their utterances. In addition, the use of the various techniques of Communicative Language Teaching such as pair work, conversations, and dialogues where learners can practice what they have learnt seems to consolidate their gains and leads to positive results. Hence derives the importance of using eclecticism in pronunciation teaching and not restricting oneself to one particular teaching method, especially when there is compatibility between activities and tasks.

The amount of explicit simplified phonetic information provided for the two experimental groups in addition to the clarifications of the misconceptions that can be caused by mispronunciations seems to have valuable results on the learners' performance. This was not the case for the control group, where technical and detailed phonetic information were provided, but no clarifications of the ambiguities that can be caused by mispronunciations were presented to students at all. Moreover, the use of communicative tasks that provide communication opportunities for learners by placing them in authentic situations resulted in better performance of the two experimental groups in comparison to the control group that only had to listen and repeat in an audio-lingual way. In this respect, the results confirm previous findings about the positive effects of advocating a communicative component in pronunciation instruction for the development of accuracy in L2 speech (Elliott, 1997 for instance). They do also corroborate previous results of Pennington and Ellis (2000) who demonstrated that raising learners' awareness towards prosodic features of the target language during training improves their interpretation of sentence meaning and also of Fraser (2000) who believes that forming new concepts of the target language while perceiving and producing speech is a key factor for successful phonological acquisition.

Second, the results also suggest that following a research-based approach in designing a pronunciation syllabus and determining the needs of a specific group of learners with respect to the characteristics of their L1 background engenders positive results. Aloulou (2003), Ghazali and Bouchhioua (2003) as well as 
Cheickrou-smaoui (2003) all showed that Tunisian EFL learners have a weak sense of English rhythm and that they have difficulties with English word stress, weak forms, and intonation . It is, however, worth mentioning that the subjects in their studies either had no pronunciation courses at all or were taught pronunciation in ad hoc ways. This was also true for the control group in this study as the same content was presented to this group but the teacher did not address the real difficulties of those learners and did not focus on how to help learners overcome them. The percentages reported by Ghazali and Bouchhioua (2003) for intelligibility measurements are also quite similar to those obtained by the participants in the current study in the pretest.

In the present study, nevertheless, addressing the special difficulties of this particular group of learners through a specific syllabus generated better performance of the two experimental groups since both comprehensibility and intelligibility improved significantly as a result of the treatment. The tendency of not making vowel reduction in function words and of stressing content words and function words equally, among Tunisian EFL learners, can be attributed to the fact that a great deal of what is expressed in English using function words is realized in Tunisian Arabic in the form of clitics. These clitics, along with their host, form a prosodic word to which only one primary stress is assigned. When reading English, Tunisian learners seem to think of every graphic word such as "for" or "to" as an independent entity eligible for stress regardless of its role in the phonological utterance. Lack of exposure to the target language as well as other factors such as difficulty in perceiving foreign sounds and prosody would strengthen this tendency. Here comes the role of explicit pronunciation instruction in helping these learners develop new concepts about the target language. Such a behavior also calls for the importance of developing syllabi for learners with different L1s since what may be problematic for Arabic learners may not be for French, or Japanese learners. Most English pronunciation books, however, address all learners equally regardless of their first language background, which resulted in maintaining the same problems for learners with specific pronunciation difficulties. There is, consequently, a great need to design pronunciation books for particular groups of learners to directly address their weaknesses and provide special assistance techniques.

Third, taking comprehensibility and intelligibility improvement as goals for explicit pronunciation instruction rather than developing a native-like pronunciation contributes to achieving positive results as demonstrated by the findings of this study. In fact, the results show that the two experimental groups obtained better ratings for comprehensibility in the posttest since the treatment tackled the potential ambiguities that a wrong vowel use, the wrong stress pattern, or the non-reduction of function words can cause to communication. Learners in the two experimental groups of the present study had the chance to learn these features and practice them during the treatment. The control group's performance, however, did not improve as much as the two other groups did. As far as intelligibility is concerned, the present study also revealed that the intelligibility of learners in the experimental groups has improved significantly as the result of the treatment, while that of the control group did not. The American listeners were able to provide more correct transcriptions of the test items produced by the subjects after the treatment. In this regard, the findings of this study corroborate the results of previous studies such as those of Munro and Derwing (2008) as well as Kang, Rubin, and Pickering (2008) where nonnative pronunciation was found to lower intelligibility or comprehensibility in L2 speech. They also confirm with the results of Gordon et al. (2012) where explicit pronunciation instruction resulted in better comprehensibility of L2 learners' speech. Comprehensibility and intelligibility are therefore reasonable goals to be opted for in pronunciation learning, especially in an EFL context where no much opportunity for interaction with native speakers is available. They constitute key factors in developing communicative competence in the target language.

The fourth angle from which the discussion of the findings is addressed is where can we see better improvement: at the segmental or at the suprasegmental level? The statistical results for comprehensibility ratings showed that there was a significant interaction between test and group, showing that each group obtained a different rating each time and that this difference depends on the kind of treatment they received. Comparison of the means for comprehensibility ratings across the three groups showed that group 2 with "focus on suprasegmentals" received the best ratings and outperformed the "segmental" and the control groups. In fact, the 
results showed that not only the comprehensibility of this group improved significantly after the treatment, but also its intelligibility since it was the group which obtained the highest mean of correct transcriptions of the sentences in the posttest ( Mean: 4.2; SD: 2.53). Focusing on the teaching of suprasegmental features such as word stress, weak forms, rhythm, and intonation seems to yield to better comprehensibility and intelligibility development than the teaching of segments only. Prosody is, in fact, known to be the organizational structure of speech since it guides the listener in his perception of oral output especially in the absence of media other than speech ( facial expressions and gestures, for example). The results of the present study confirm previous results on the effects of teaching suprasegmental in general pronunciation improvement (Anderson-Hsieh et al., 1992; Derwing et al., 1998; Gordon et al., 2012).

All those studies showed that focusing on the teaching of prosody improves accuracy. Instruction in segmental accuracy, especially when substituting one sound by another results in a change of meaning is also important and beneficial as demonstrated by the performance of the 'segmental' group in this study. This group had more practice in segmental contrast and improved significantly from pre to posttest in both comprehensibility and intelligibility. Producing comprehensible and intelligible segments and suprasegmentals is believed to reduce inhibition and encourage learners to use their L2 in communicative contexts and consequently become more fluent. This reinforces the importance of the pronunciation component (both at the segmental and suprasegmental levels) to the general development of speaking skills in the second language learning.

This study has tried to tackle the effectiveness of pronunciation instruction by checking four complementary aspects which are the teaching approach, the syllabus that is based on the potential difficulties of a specific group of learners, the goals behind instruction and the type of focus (segmental vs. suprasegmental). The participants in were, however, all volunteers. So, their performance could have been boosted by their high motivation in taking a pronunciation course and by their desire to strengthen their speaking skills in English. Although this variable was controlled by assigning them randomly to three different groups and despite the fact that the performance of the control group did not improve as significantly as the two experimental groups did, it could have been more enlightening if intact groups were taken as participants and if the number of learners was higher in each group. Obstacles such as convincing teachers and administrators to use their intact groups and classes in research experiments are difficult to overcome. Significant research results even on volunteers would hopefully encourage administrators and teachers to raise these barriers. Other limitations of the study include the small sample size of sentences used in the intelligibility test, the limited number of raters, and the use of different instructors to teach the three groups. It would have also been useful to investigate the performance of the learners in spontaneous speech if they had a higher proficiency level in English. These limitations would hopefully be addressed in future research.

\section{Conclusion}

Pronunciation has often been ignored in L2 teaching, either because of its association with the mechanical drills associated with the Audio-lingual method or because of its non-compatibility with Communicative Language Teaching where focus is placed on fluency at the expense of accuracy. Acquiring an accurate pronunciation has also been considered as a frustrating goal for many adult learners of English because reaching a native-like accent was set as a goal in many ESL classes. Recent research has, however, increasingly demonstrated that positive results can be achieved through pronunciation instruction if communicative and cognitive approaches rather than implicit or audio-lingual methods are adopted and if intelligibility and comprehensibility development were set as objectives of training rather than native-like pronunciation. In addition, recent research has interestingly shown that focusing on teaching the prosody of English rather than just its segments results in better pronunciation and significantly improves the learners' intelligibility and comprehensibility in the target language. Further research is, however, needed to get more insight into various other factors that interfere with successful pronunciation instruction such as the time factor; short term vs. long term instruction, as well as factors of exposure, motivation, individual differences and attitude toward the target language which are also known to be influential in achieving positive results. The results of pronunciation 
Bouchhioua, N.

instruction research so far reached present a helpful background for applied linguists, curriculum designers, and language teachers to design syllabi that suit the needs of their learners and restrict their areas of focus to the most challenging aspects. This would save time and energy for both the teacher and the learner and would, hopefully, bridge the gap between theory and practice especially in the domain of L2 phonology where a wide disconnection between laboratory research and classroom practice is often noticed.

Acknowledgments: I would like to thank the Tunisian students and teachers, as well as the American listeners for their participation in this study. Special thanks are also addressed to the members of Second Language Psycholinguistics Lab at Indiana University for their useful comments on the design of the study.

\section{References}

Almbark, R., Bouchhioua, N., \& Hellmuth, S. (2014). Acquiring the phonetics and phonology of English word stress: comparing learners from different L1 backgrounds. Proceedings of the International Symposium on the Acquisition of Second Language Speech: Concordia Working Papers in Applied Linguistics, 5 , 19-35.

Aloulou, M. (2003). The intonation patterns of Tunisian Arabic and English: a comparative study. Unpublished Masteral dissertation, ISLT, University of Carthage, Tunis.

Anderson-Hsieh, J. R., \& Koehler, K. (1988). The effect of foreign accent and speaking rate on native speaker comprehension. Language Learning, 38, 561-593. http://dx.doi.org/10.1111/j.1467-1770.1988.tb00167.x

Anderson-Hsieh, J., Johnson, R., \& Koehler, K. (1992). The relationship between native speaker judgments of nonnative pronunciation and deviance in segmentals, prosody and syllable structure. Language Learning, 42, 529-555. http://dx.doi.org/10.1111/j.1467-1770.1992.tb01043.x

Asher, J., \& Garcia, R. (1969). The optimal age to learn a foreign language. Modern Language Journal, 53, 334-341. http://dx.doi.org/10.1111/j.1540-4781.1969.tb04603.x

Baker, A. (2014). Exploring teachers' knowledge of second language pronunciation techniques: Teacher cognitions, observed classroom practices, and student perceptions. TESOL Quarterly, 48(1), 136-163. http://dx.doi.org/10.1002/tesq.99

Bouchhioua, N. (2008). The acoustic correlates of stress and accent in Tunisian Arabic: a comparative study with English. Doctoral thesis, ISLT, University of Carthage, Tunis.

Celce-Murcia, N., Brinton, M. D., \& Goodwin, J. M. (2010). Teaching pronunciation: A reference for teachers of English to speakers of other languages (2nd ed). Cambridge: Cambridge Press.

Cheikhouhou-Smaoui, M. (2003). Tunisian Arabic and English speech rhythm: A comparative analysis. Doctoral thesis, Faculty of Letters, University of La Manouba.

Couper, G. (2003). The value of an explicit pronunciation syllabus in ESOL teaching. Prospect, 18, 53-70.

Couper, G. (2009). Teaching and learning L2 pronunciation: Understanding the effectiveness of socially constructed metalanguage and critical listening in terms of a cognitive phonology framework. Unpublished Doctoral thesis, University of New England, Armidale, Australia.

Couper, G. (2011). What makes pronunciation teaching work? Testing for the effect of two variables: Socially Constructed Metalanguage and Critical Listening. Language Awareness, 20(3), 159-182. http://dx.doi.org/10.1080/09658416.2011.570347

Derwing, T. M., \& Munro, M. J. (1997). Accent, intelligibility, and comprehensibility: Evidence from four L1s. Studies in Second Language Acquisition, 19, 1-16. http://dx.doi.org/10.1017/s0272263197001010

Derwing, T. M., \& Munro, M. J. (2005). Second language accent and pronunciation teaching: A research-based approach. TESOL Quarterly, 39, 379-397. http://dx.doi.org/10.2307/3588486

Derwing, T. M., Munro, M. J., \& Wiebe, G. E. (1998). Evidence in favor of a broad framework for pronunciation instruction. Language Learning, 48, 393-410. http://dx.doi.org/10.1111/0023-8333.00047

Elkassami, W. (2014). The perception of connected speech and weak forms by Tunisian EFL learners. Unpublished Masteral thesis, University of La Manouba. 
Effects of explicit pronunciation instruction on the comprehensibility and intelligibility of Tunisian EFL learners

Elliott, T. (1995). Foreign language phonology: Field independence, attitude, and success of formal instruction in Spanish pronunciation. Modern Language Journal, 79, 530-42. http://dx.doi.org/10.1111/j.1540-4781.1995.tb05456.x

Elliott, T. (1997). On the teaching and acquisition of pronunciation within a communicative approach. Hispania, 80(1), 95-108. http://dx.doi.org/10.2307/345983

Fraser, H. (2000). Coordinating improvements in pronunciation teaching for adult learners of English as a second language. ANTA Innovative Project. Canberra: DETYA.

Fraser, H. (2006). Helping teachers help students with pronunciation: a cognitive approach. Prospect, 21, 80-95.

Fraser, H. (2009). Pronunciation as categorization: The role of contrast in teaching English /r/ and /1/. In A.

Mahboob \& C. Lipovsky (Eds.), Studies in applied linguistics and language learning (pp. 289-306).

Newcastle, UK, Cambridge Scholars Publishing.

Ghazali, S., \& Bouchioua, N. (2003). The learning of English prosodic structures by speakers of Tunisian Arabic. In the Proceedings of the $13^{\text {th }}$ International Congress of Phonetic Science (pp. 961-964), Barcelona.

Gordon, J., Darcy, I., \& Ewert, D. (2013). Pronunciation teaching and learning: Effects of explicit phonetic instruction in the L2 classroom. In J. Levis \& K. LeVelle (Eds.), Proceedings of the 4th Pronunciation in Second Language Learning and Teaching Conference (pp. 194-206). Ames, IA: Iowa State University.

Kang, O., Rubin, D., \& Pickering, L. (2010). Suprasegmental measures of accentedness and judgment of language learner proficiency in oral English. Modern Language Journal, 94, 554-566. http://dx.doi.org/10.1111/j.1540-4781.2010.01091.x

Langacker, R. (1987). Foundations of cognitive grammar: Theoretical prerequisites (Vol. 1). Stanford: Stanford University Press.

Larsen-Freeman, D., \& Long. M. (1991). An introduction to second language acquisition research. London: Longman.

Lord, G. (2005). (How) Can we teach foreign language pronunciation? On the effects of a Spanish phonetics course. Hispania, 88, 557-567. http://dx.doi.org/10.2307/20063159

Major, R. C. (1987). Phonological differentiation of a bilingual child. Ohio State University Working papers in Linguistics, 22, 88-122.

Munro, M. J., \& Derwing, T. M. (2008). Segmental acquisition in adult ESL learners: A longitudinal study of vowel production. Language Learning, 58, 479-502. http://dx.doi.org/10.1111/j.1467-9922.2008.00448.x

Oyama, S. (1976). A sensitive period for the acquisition of a nonnative phonological system. Journal of Psycholinguistic Research, 5, 261-285. http://dx.doi.org/10.1007/BF01067377

Pennington, M. C. (1998). The teachability of phonology in adulthood: A re-examination. IRAL, 36(4), $323-341$. http://dx.doi.org/10.1515/iral.1998.36.4.323

Pennington, M. C., \& Ellis, N. C. (2000). Cantonese speakers' memory for English sentences with prosodic cues. Modern Language Journal, 84, 372-389. http://dx.doi.org/10.1111/0026-7902.00075

Phan, H., \& Vo, S. (2012). Pronunciation errors and perceptual judgments of accented speech by native speakers of English. TESOL in Context, S3, 1-9.

Saito, K., \& Lyster, R. (2012). Effect of form-focused instruction and corrective feedback on L2 pronunciation development of /r/ by Japanese learners of English. Language Learning, 62, 595-633. http://dx.doi.org/10.1111/j.1467-9922.2011.00639.x

Scarcella, R. C., \& Oxford, R. L. (1994). Second language pronunciation: state of the art in instruction. System 22(2), 221-230. http://dx.doi.org/10.1016/0346-251X(94)90058-2

Selmi, Y. (2012). Describing the Tunisian variety of English. Unpublished Masteral thesis, ISLT, University of Carthage.

Taylor, J. (2002). Cognitive grammar. Oxford: Oxford University Press.

Terrell, T. D. (1989). Teaching Spanish pronunciation in a communicative approach. In P. C. Bjarkman \& R. M. Hammond (Eds.), American Spanish pronunciation: Theoretical and applied perspectives (pp. 196-214). Washington, DC: Georgetown University Press. 
1. She cut the fur of her cat.

Appendix A: Pretest items

2. She is going to fast*

3. Wait here until I come back

4. The government lends land to poor farmers.

5. She studies in Oxford but lives in Stratford

6. What he said was really sad.

7. The teacher asked for questions*

8. I can't walk up the hill with those heels.

9. Those are Rosa's vases*

10. I went to the shoes store and chose lovely shoes.

11. Russia's need increase*.

12. The right rules make the right reign.

13. Use the numbers one to four*.

14. Found them!

15. A: Do you know that Sally's father died in a car accident?

B: yes, I do, her sister was two, then.*

(*) indicates the sentences used to test intelligibility.

1. She cut the fur of her cat.

Appendix B: Posttest items:

2. He made a backward movement.

3. She is going to fast*

4. Wait here until I come back

5. How is your dad?

6. The government lends land to poor farmers.

7. What he said was really sad.

8. I'm dealing with them

9. I can't walk up the hill with those heels

10. Those are Rosa's vases*

11. I do the washing up every night

12. I went to the shoes store and chose lovely shoes.

13. Russia's need increase*.

14. The right rules make the right reign.

15. Use the numbers one to four*.

16. Found them!

17. A: Do you know that Sally's father died in a car accident?

B: yes, I do, her sister was two, then.*

18. She got you!

19. The teacher asked for questions*

20. She studies in Oxford but lives in Stratford.

(*) indicates the sentences used to test intelligibility. 